Cuadernos de Ilustración y Romanticismo

Revista Digital del Grupo de Estudios del Siglo XVIII

Universidad de Cádiz / ISSN: 2173-0687

$n^{\circ} 26(2020)$

\title{
ENTRE AVATARES DE LA MODERNIZACIÓN Y DEMANDAS POLÍTICAS: LA TRAYECTORIA DE ÁNGEL JULIO BLANCO
}

\author{
María Carolina SÁNCHEZ \\ (Universidad Nacional de Tucumán(UNT)-CONICET)
}

Recibido: 01-01-2020 / Revisado: 10-07-2020

Aceptado: 16-06-2020 / Publicado: 21-12-2020

Resumen: Al igual que muchos otros escritores argentinos emergentes a lo largo del período de la «Organización Nacional» (1852-1880), Ángel Julio Blanco (1830-1898), figura a la que está dedicado este trabajo, no aparece registrado en las historias literarias nacionales. Se examinarán aquí una serie de testimonios proporcionados por el autor que reflexionan acerca de las condiciones bajo las que se desenvuelve la práctica literaria de su tiempo. Su lúcida conciencia provee un diagnóstico de interés para la comprensión del estado de cosas imperante en el ámbito de las bellas letras que debieron afrontar quienes se iniciaban con la aspiración de alcanzar reconocimiento. Consideraciones en torno a un conjunto de factores interdependientes ligados a la cuestión de la autoría y la coyuntura previa a la profesionalización, las características del público lector, la legitimación dentro del círculo letrado, las concepciones de literatura y los modos de edición y comercialización reponen datos iluminadores para trazar un proceso de constitución del campo literario argentino.

Palabras Clave: Autores olvidados, Organización Nacional, Ángel J. Blanco, práctica literaria.

\section{BETWEEN THE AVATARS OF MODERNIZATION AND POLITICAL DEMANDS: THE CAREER PATH OF ANGEL JULIO BLANCO}

ABSTRACT: Like many other emerging Argentinean authors throughout the period known as «National Organization» (1852-1880), Angel Julio Blanco (1830-1898), the figure whom this paper deals with, is not registered in the national literary histories. The purpose of this paper is to highlight the relevance of a series of testimonies provided by Blanco, in which this Argentinian writer portrays his views regarding the literary practice of his times. His lucid perspective provides the reader with an interesting diagnosis of the Belle Lettres affair related to novice writers who were seeking recognition. It also brings about considerations on matters of authorship, on the context existing before professionalism, on characteristics of the reader, on legitimation among the literate circle, on literature production, editing and commercialization, all of which allows the reader to visualize a process of constitution of the Argentine literary field. KEYWORDS: Forgotten authors, National Organization, Ángel J. Blanco, literary practice. 
La figura y obra de Ángel Julio Blanco (1830-1898), escritor argentino de la segunda mitad del siglo xIx, resulta prácticamente desconocida en el presente. Su actividad más intensa, primero como redactor de La Ilustración Argentina, semanario novedoso dedicado a la literatura, y luego como novelista — autor de Una venganza funesta, novela orijinal (1856), Emeterio de Leao, continuación de Una venganza funesta, novela original (I857a) y Luis y Estevan (I859) - , se corresponde con la instancia en que la práctica literaria comienza a rearticularse una vez vencida la tiranía de Rosas, tras diecisiete años en el poder. ${ }^{2}$ En efecto, las fechas de publicación de sus artículos periodísticos y novelas ponen de manifiesto que, en su conjunto, ellos se contextualizan en la coyuntura inicial de un período que la historiografía circunscribe bajo la designación de «Organización Nacional», comprendido entre 1852 y I880, ${ }^{3}$ cuando cristaliza la construcción del Estado moderno.

La falta de noticia alrededor de Blanco se debe, en parte, a la omisión de su nombre en las diferentes versiones de la historia de la literatura argentina, en cuyo marco, como se sabe, se define la supervivencia de un escritor y sus textos para la posteridad. Tampoco se halla registro de él en los diccionarios biográficos de autores argentinos. ${ }^{4}$ No es el suyo el único caso; otros jóvenes que en esos años hacían su aparición en el ámbito de las bellas letras, fueron igualmente ignorados en las reseñas referidas al período. ${ }^{5}$ Hito decisivo para la visibilización de esta promoción marginada, la investigación de Hebe Molina (20II), dedicada a la emergencia de la novela en el sistema literario argentino entre I837 y 1872, hizo posible la recuperación de sus actores y producciones — en su mayor parte pertenecientes a este género- $\mathrm{y}$ con ello la reconstrucción de una escena literaria más compleja que la ofrecida por aquellas perspectivas ajustadas a la selección canónica, al capturar la coexistencia de distintas generaciones y grados de prestigio de sus miembros, movimientos asociativos, proyectos creadores y posiciones en debate. ${ }^{6}$

Siguiendo ese enfoque sincrónico, este trabajo se propone destacar la relevancia de una serie de testimonios proporcionados por Blanco, que plasman reflexiones acerca de las condiciones bajo las que se desenvuelve la práctica literaria de su tiempo. Su lúcida conciencia provee un diagnóstico de interés sobre el estado de cosas imperante en el

I Nótese la vacilación ortográfica en la escritura de la palabra «original», consignada en el primer título con «j»y en el segundo con «g». Hacia mediados del siglo xIx este adjetivo fue usado en la portada de algunas novelas argentinas para señalar que pertenecían a un autor local, que se abría paso en medio de la proliferación de folletines europeos (Molina, 20Ir: 54). Es oportuno aclarar aquí que en las citas de los textos de Blanco que más adelante se reproducirán como también en la de otras fuentes del período, se respetarán sus usos ortográficos y erratas.

2 Rosas ya había actuado en la vida política porteña desde I829, pero es con su segundo gobierno y la obtención de la suma del poder público, hacia I835, que tiene lugar la persecución sistemática de la oposición unitaria.

3 Este período, que se extiende por las tres décadas arriba señaladas, aparece caracterizado por la historiografía como una etapa en la que Argentina atraviesa un proceso de transformación modernizadora, producto de la expansión capitalista, vinculada tanto con la centralización y consolidación del Estado como con el crecimiento demográfico, el desarrollo de las ciudades, la extensión del sistema de enseñanza, entre otros fenómenos.

4 Blanco no posee una entrada en el Nuevo diccionario biográfico argentino (I750-1930) de Vicente Cutolo (I968I985), por ejemplo.

5 Si bien en la inaugural Historia de la literatura argentina (I9I7-I922) escrita por Ricardo Rojas algunas de estas figuras olvidadas reciben cierta atención, en las sucesivas reconstrucciones del proceso literario nacional tales como la colección Capitulo: Historia de la literatura argentina, publicada por el Centro Editor de América Latina desde I968, en la que colaboraron distintos especialistas, y la Historia crítica de la literatura argentina (2003) dirigida por Noé Jitrik, en su volumen dedicado al siglo xıx — bajo el título La lucha de los lenguajes — a cargo de Julio Schvartzman, se asiste a una reducción de los nombres que han de perdurar como exponentes de la literatura de la centuria.

6 Comentando esa laguna en la historiografía literaria por la falta de registro de este patrimonio, Eugenia Ortiz Gambetta señala: «hay una convicción sostenida, aún hoy, sobre la secuenciación de la novela local, según la cual se plantea un vacío textual entre las décadas de I850 y 1880, es decir, los años llamados de la Organización Nacional, entre la aparición de Amalia y las obras de la generación del 80, con algunas contadas excepciones dispersas y señaladas como obras "menores"» (20I3: I2). 
ámbito de las bellas letras que debieron afrontar quienes se iniciaban con la aspiración de alcanzar reconocimiento a través de su obra. Consideraciones en torno a un conjunto de factores interdependientes ligados a la cuestión de la autoría ${ }^{7}$ y la coyuntura previa a la profesionalización, las características del público lector, la legitimación dentro del círculo letrado, las concepciones de literatura y los modos de edición y comercialización, aportan datos iluminadores para trazar el proceso de constitución del campo literario argentino. Asimismo, el procesamiento de estas fuentes indagará en las autofiguraciones de Blanco como autor, destinadas a construir una imagen de sí en el cuadro de situación expuesto como estrategia para posicionarse. Los textos escogidos para el presente estudio son: una sátira de costumbres publicada en La Ilustración Argentina, titulada «La Moda, el Tono y el Talento», aparecida el 25 de septiembre de 1853 ; los paratextos y proyecto creador que sustenta a las novelas arriba mencionadas, y una carta dirigida a Carlos L. Paz, publicada como prólogo de Santa y mártir de veinte años, novela con la que este último hace su debut en el panorama de las letras en 1857. A modo de piezas de un rompecabezas, en un trasfondo de datos faltantes, esos escritos son portadores de un rastro que permite reponer parcialmente una figura de autor y la conflictividad para constituirse como tal.

TRAZOS DE UNA ÉPOCA: POLÍTICA Y PRÁCTICA LITERARIA. INTERVENCIONES DE BLANCO

Los tiempos que se inauguran luego de la batalla de Caseros y el consecuente fin del auge rosista están marcados por una precaria estabilidad; más que una etapa de progreso continuo al cual el nombre de «Organización Nacional» parecería aludir, se trata, como sostiene Tulio Halperin Donghi, de un proceso que «no tenía nada de la serena y tenaz industriosidad que se espera de una cuyo cometido es construir una nación» (2012: 32), o, como sintetiza Roy Hora, consiste en realidad en «tres décadas de agrias polémicas y duros conflictos (no pocas veces zanjados en campos de batalla), que se desplegaron sobre un fondo marcado por vertiginosas transformaciones del escenario local e internacional» (2012: 17). Apenas restablecido el orden republicano, sacuden al país profundas turbulencias políticas que derivan en la Secesión de Buenos Aires (I852-I860), preludiando el constante disenso que se avecina. ${ }^{8}$

Si bien en la imaginación de la elite política y letrada opositora al tirano la nueva era se habita con una fuerte voluntad fundacional, como un futuro promisorio en el que hallarían concreción los proyectos de país diseñados desde el exilio, no solo las divergencias de sus integrantes entre sí, sino también el ajuste de las transformaciones ideadas respecto de la materialidad de la experiencia histórica demostrarán la conflictividad de la empresa. ${ }^{9}$ El protagonismo adquirido por los miembros de la Generación del 37 en

7 Siguiendo a Graciela Batticuore, en su versión moderna esta noción implica «La reivindicación del “nombre” de autor, el aprecio de la fama que puede adquirirse a través de una obra (...) así como la convicción de que la escritura es un "trabajo" que merece cobrarse con dinero (...) un modo estrictamente romántico de concebir la autoría, que proclama el reconocimiento de la originalidad creadora del artista y pide sin rodeos derechos sobre la obra» (2006: 22). Como ha precisado el estudio clásico de Roger Chartier (I994), la concesión del derecho de propiedad a los autores se efectúa hacia mediados del siglo Xviı y da lugar a esta nueva manera de entender la autoría.

8 Como precisa Néstor Auza, «En septiembre de I852 tuvo lugar el pronunciamiento militar de los porteños en disconformidad con la política nacional de Justo José de Urquiza y, como una contrarrevolución al mismo, el I de diciembre el general Lagos, a su vez, efectuaba otro pronunciamiento militar sitiando la ciudad porteña en un gesto que denota la pluralidad de corrientes políticas que se agitaban» (I999: 103). Ricardo Salvatore, por su parte, denomina al período I852-I865 «transición liberal», signado por el fundado temor al retorno del rosismo (20Io).

9 Alberto Lettieri puntualiza el desencuentro entre tales proyectos en estos términos: «Tras de las coincidencias sobre la urgente necesidad de una transformación, e, incluso, sobre las variables fundamentales sobre las que ella debería descansar - la inversión extranjera, la inmigración, el avance de los transportes, la educación y la institucionalización política-, los proyectos elaborados expresaron marcadas diferencias en cuanto a la forma en que esos factores deberían 
esta instancia constructiva del Estado nación da cuenta de la estrecha vinculación entre «los hombres de pluma y la vida política» (Altamirano, 2008: 10) que atravesó todo el siglo xIx. Ellos, entregados a la «avasalladora pretensión de constituirse en guías del nuevo país (y su justificación por la posesión de un salvador sistema de ideas)» (Halperin Donghi, 20I2: 40), comprometen su labor incursionando en la esfera del poder, en pos de la creación de una república civilizada.

En forma simultánea a las oscilaciones de la lucha política, se asiste en el período al «desarrollo de una sociedad civil relativamente autónoma cuyo síntoma más evidente fue la expansión de la actividad asociativa y de la prensa» (Sábato, 2008: 387), como también «una expansión del (...) mercado de consumo de bienes culturales», que se verifica en el «notorio incremento en el número de librerías e imprentas» (Eujanián, r999: 558). ${ }^{\text {ro }}$ Subyace a estos fenómenos la paulatina conformación de un público lector, que comienza a gestarse mediante la puesta en marcha de los planes de instrucción pública instrumentados desde la política gubernamental como medida indispensable en la invención del ciudadano." En la coyuntura de reciente lanzamiento del cometido alfabetizador - la década de I850, aquí focalizada-, tiene gran relevancia para despertar el interés por la lectura las estrategias discursivas y empresariales desplegadas por las expresiones del capitalismo impreso. Las nuevas publicaciones promovieron una mayor participación, dado que, como novedades, «contrastaban con el ritmo monocorde del pasado» (Auza, I999: I03).

Ya algunos de estos signos de modernización y cambio cultural se evidencian hacia 1852. En lo que atañe específicamente a la práctica literaria, se propagan redes de sociabilidad nucleadas en espacios institucionales autoorganizados, cuya actividad, en muchos casos, se canaliza a través de revistas. Como señala Néstor Auza, «Si bien lo literario se constata como una constante en el periodismo en general, las revistas literarias son, como variedad periodística, una modalidad que hace su aparición luego de la caída de Rosas» (1999: 20). ${ }^{\text {I2 }}$ En la década de I85o, se editan: La Brisa — de un solo número datado el 4 de septiembre de 1852-, dirigida por Juan María Gutiérrez y Miguel Cané; La Ilustración Argentina. Semanario critico y literario, fundada por Benito Hortelano y Antonio Serra y Oliveros, publicada entre septiembre y diciembre de $18533^{\mathrm{I3}}$ El Recuerdo, creado por el uruguayo Heraclio Fajardo, de seis meses de duración entre enero y junio de 1856; El Estímulo, también proyecto de Fajardo en circulación entre febrero y agosto de 1858 ;

ser combinados, ofreciendo un abanico de opciones escasamente compatibles. Particularmente en lo referido a las características del liderazgo político y del consenso social indispensable para abordar la transformación definitiva de la República. Estas diferencias se irían agudizando en las décadas siguientes, provocando frecuentes enfrentamientos que condujeron a la adopción de posiciones polarizadas» (I999: 100).

ıo Según consigna Alejandro Eujanián, existían en Buenos Aires hacia I855 «II librerías, io imprentas y dos litografías», cifra que en I859 «ascendió a I5 librerías, I2 imprentas y dos litografías» (I999: 559).

II Eujanián advierte que las cifras arrojadas por la alfabetización solo pueden ser consideradas potencialmente de cara a estimar el crecimiento de la práctica de la lectura: «aun considerando los límites (...) respecto al progreso del sistema educativo en el período, es un hecho indudable que hay una ampliación reflejada en el ingreso de mayor cantidad de personas a ciertos niveles de escolarización y, a través de ella, a la incorporación de nuevas aptitudes para la lectura. El problema es si de los datos cuantitativos que certifican la expansión, debemos inferir necesariamente una mayor dimensión del público lector y, más aún, la conformación de un público constituido por el acceso a la lectura de nuevos contingentes que anteriormente se encontraban irremediablemente excluidos» (1999: 557).

I2 Auza comenta que desde el comienzo de la nueva etapa política «se produjo un fenómeno cultural inusitado, caracterizado por la fuerte explosión periodística. Impresos de todos los géneros y respondiendo a los más diversos intereses, fuera de los estrictamente políticos, hacen su aparición en el reducido escenario porteño y si bien no todos alcanzan una larga vida, son la expresión del clima en que se vive» (I999: 22). Recogiendo los datos proporcionados por Antonio Zinny, en 1852 se publicaron en Buenos Aires 35 periódicos.

I3 La Ilustración Argentina tendrá una segunda época con el mismo nombre y otro subtítulo - Museo de familias- y se publicará entre el II de diciembre de I853 y el 2 de abril de I854. 
La Guirnalda, bajo la dirección de José Manuel y Santiago Estrada, editado de noviembre de 1858 a marzo de 1859; y Museo Literario, editado por Carlos L. Paz y Lisandro Paganini, que se extiende de enero a mayo de $1859 \cdot{ }^{14}$ En su mayor parte la conexión de estos nuevos productos con un público cuyo número es escaso, pese a indicios alentadores de su activación, se efectúa mediante un sistema de venta por suscripción, el cual, como analiza Eujanián, «aseguraba un mercado, si bien restringido, al menos relativamente estable por un período y (...) tenía el beneficio adicional del pago por adelantado (...) la empresa consistía más en colocar de antemano el producto asegurándose de este modo el concurso de los suscriptores que en la inversión de capital» (I999: 572). ${ }^{\text {I5 }}$

De duración efímera y con una frecuencia de aparición semanal, quincenal o mensual, según los casos, las revistas se perfilan como espacios idóneos para el surgimiento de nuevas figuras, y se convierten en atisbo de una embrionaria diferenciación de la actividad. Por lo general, son concebidas para dar cabida a las nuevas generaciones que asoman en el mundo de las letras, cuestión explícita en casi todos los programas y plasmada en nombres alusivos como «estímulo» o «guirnalda», por ejemplo. La aparición de Blanco en la escena literaria acontece en el marco de La Ilustración Argentina, cuyo proyecto se especifica claramente en el subtítulo que la acompaña: Semanario crítico y literario ${ }^{16}$ "Crítico» indica la orientación hacia el estudio de costumbres, mientras «literario» apunta a la publicación de las composiciones poéticas y novelas de los jóvenes. La nota titulada «Los editores» agradece a los flamantes colaboradores ${ }^{17}$ la producción de material y destaca el papel de la publicación como plataforma de ingreso en las letras nacionales: «Creemos que el público acogerá sus trabajos con benevolencia, animándolos para que continuen con el empeño que han empezado, y si asi lo hacen, aseguramos

I4 Puede incluirse en este grupo la revista Pica Flor, la cual, editada entre enero y marzo de I855, se caracteriza por el anonimato tanto de su director, quien firma bajo el seudónimo El Aprendiz, como de sus colaboradores. Durante las décadas siguientes de la Organización Nacional se publican también Revista de Ciencias y Letras (noviembre de I864 a enero de 1865); Revista de la Sociedad Estímulo Literario (julio a diciembre de I87I); La Revista del Río de la Plata (I87I-I877); El Plata Ilustrado (octubre de I871 a julio de I873); El Ateneo Argentino (abril de I872 a octubre de I873); Porvenir Literario (septiembre de 1872 a febrero de I873); Revista de la República (marzo a septiembre de I873); Revista Literaria (julio de I874 a septiembre de 1875); Revista Cientifico Literaria (junio a septiembre de I875); El Plata Literario (mayo a diciembre de 1876); El Álbum del Hogar (julio de 1878 a abril de i895); Revista de Ciencias, Artes y Letras, (marzo a octubre de 1879) y, finalmente, Revista Literaria (junio a octubre de I879). A este movimiento debe agregarse el naciente periodismo femenino con Album de señoritas (1854), La Ondina del Plata (I875-I879) y La Alborada del Plata (I877-I879).

I5 Contracara de esta activación de la vida cultural, el escaso desarrollo del público lector constituye una situación expresada con claridad por Fajardo al presentar El Estímulo: «Si la aficion á leer estuviera en relacion con la aficion á escribir, fácilmente preveríamos una época muy próxima y brillante para la gloria de las letras en esta orilla del Plata (...)

Pero desgraciadamente así no sucede. (...) puede decirse que (...) son mas los que escriben que los que leen» («La Dirección», 9 de febrero de I858).

I6 Según lo señalado por Auza, el nombre La Ilustración Argentina hace referencia a la voluntad del editor de acompañar con grabados cada publicación, movido por el interés de introducir novedades en la presentación de los impresos en el Río de la Plata (I999: I05). En cuanto a la figura de Hortelano, fundador de la revista, Eujanián lo coloca entre un grupo de emigrados al país que actúa en el rubro de la impresión: «libreros e impresores sumaban un conjunto de características compartidas por quienes se dedicaban a dicha actividad y también con otros sectores del comercio y la industria. En su mayoría, las librerías se hallaban regenteadas por extranjeros llegados al país en la etapa previa o inmediatamente posterior a Caseros, siendo predominante la presencia de españoles y franceses» (I999: 564), «se trataba en gran parte de trabajadores calificados que llegaban (...) con alguna experiencia desarrollada en sus lugares de origen e incluso habiendo cursado estudios que los habilitaban como imprenteros o litógrafos». Específicamente del editor de La Ilustración... dice: «Un referente insoslayable, en la medida que condensa las características del editor-librero en el período (...) es la figura de Benito Hortelano», dueño de la librería Hispano-Americana (565).

I7 Los colaboradores son: Palemón Huergo, Adolfo Alsina, Juan Agustín García, Manuel Augusto Montes de Oca, Hilario Ascasubi, José M. Gutiérrez y Leopoldo Montes de Oca. 
que antes de un año, brillarán algunas lumbreras de la literatura Argentina» (II de septiembre de 1853). ${ }^{18}$

A través de los diferentes números de la revista se pueden encontrar reseñas de la creciente urbe porteña, de sus bailes, comentarios de espectáculos teatrales y de ópera y notas referidas a diferentes curiosidades. Si bien la producción literaria ocupa un lugar predominante y es el sello distintivo del semanario, hay también semblanzas biográficas y ensayos históricos. ${ }^{19}$ Además de algunos poemas, Blanco se dedicará a la escritura de textos orientados al examen de los hábitos nacionales. Podría decirse que a pesar de los veintitrés años con que cuenta cuando es colaborador del semanario, sus artículos revelan sólidas convicciones y madurez en el dominio de la pluma como para plasmar una aguda crítica de costumbres.

Valga traer a colación una anécdota que perfila la firmeza inconmovible de sus juicios: sin concesiones, sus críticas le valieron en cierta oportunidad un alejamiento momentáneo de la revista dado el tenor de una nota suya titulada «La prensa del país» (9 de octubre de 1853), donde resalta la labor de algunos reconocidos literatos publicistas por su adhesión a la verdad y acusa a otros por la desfiguración de los hechos según el prisma de su partidismo y la consecuente manipulación de una opinión pública poco preparada. La omisión de algunas figuras entre los representantes de un periodismo de servicio cívico, como las de Mitre y Sarmiento, ya poseedores de un incontrastable prestigio en aquel entonces, provocó incomodidad entre sus compañeros prontos a reprobar la polémica perspectiva en una nota titulada «Protesta» ( 16 de octubre de 1853 ). ${ }^{20} \mathrm{E} 1$ episodio conducirá al intransigente colaborador a adoptar la decisión de abandonar la revista para regresar más adelante, una vez disuelto el grupo realizador e iniciar la segunda época.

Blanco se retira definitivamente de la redacción de La Ilustración Argentina en abril de i854. De acuerdo con datos aportados por Molina, resurge en la actividad cultural porteña en I856 como secretario del Club Parroquial de Montserrat. En esta red asociativa, dirigida a contribuir al progreso moral de la sociedad, participan jóvenes que luego intervendrán en el periodismo literario. En ese mismo año y en el siguiente, publica su primera y segunda novela, concebida esta última como prolongación de la historia contada en su antecedente. Hacia I858 se integrará al Ateneo del Plata, un círculo literario congregado por Fajardo. ${ }^{2 \mathrm{~T}}$

Una breve exposición de las concepciones y programa de esta última agrupación como también de las tensiones suscitadas en su seno resultan pertinentes para perfilar aquellos principios a los que Blanco adhirió y los posicionamientos que asumió en un trasfondo

I8 Se agregará aquí un ejemplo de otra revista. Evocando la experiencia de su publicación precedente y procurando darle continuidad en El Estímulo, Fajardo expresa: «Hace dos años, al publicar el Recuerdo (...) solo nos guiaba el deseo de propender (...) al fomento de las bellas letras en las riberas del Plata; y tuvimos la satisfaccion de ver aparecer en las columnas de nuestro semanario lozanas y modestas inteligencias, ignoradas hasta entonces» («La Dirección», 9 de febrero de r858). Hecho este balance y a fin de repetir aquel buen resultado, vuelve a invitar a la juventud para participar en este nuevo impreso que presenta a la sociedad: «Abrimos nuestras columnas á todas las inteligencias de esta tierra: daremos cabida en ellas á todo lo que llene ciertas condiciones literarias y no ofenda la moral, reservándonos para ello el derecho de censura» («La Dirección», 9 de febrero de 1858).

I9 La presencia de materiales procedentes de otras disciplinas, como la historia por ejemplo, coexiste con la voluntad de delimitar un ámbito específico para las letras. Se comprueba en este punto que «hasta bien entrado el siglo xix la literatura tenía en Hispanoamérica un sentido muy amplio, e incluía tanto producciones 'literarias' como históricas, científicas o filosóficas» (Goldgel, 2013: 38).

20 Distanciándose de los juicios vertidos por Blanco, sus compañeros expresan «Creemos asi mismo que haríamos una injuria á los señores Alsina, Sarmiento, Mitre, Vélez Sarsfield, Wright, Tejedor, etc, si pretendiésemos (...) anonadar la acusación que gratuita e inmerecidamente les hace el sr. Blanco» («Protesta», I6 de octubre de I853). 2I Al trazar su reconstrucción de la cultura literaria del período, Molina pone de relieve «el legado de un grupo de uruguayos refugiados en Buenos Aires» (20Ir: 98) como promotores influyentes. Fajardo y Alejandro Magariños Cervantes, se destacan especialmente. 
en el que se asiste a un debate alrededor de la función de la literatura. El Ateneo surge como iniciativa de fomento a la vocación creadora de las nuevas generaciones; el propósito es forjar a los sucesores en el desarrollo de la literatura nacional. Según se consigna en las actas de las sesiones plasmadas en El Estímulo, «Un número considerable de jóvenes de los más inteligentes y aventajados, han acudido á nuestro humilde llamado» («Ateneo del Plata», 9 de junio de 1858). La institución se ajusta a los valores modernos vinculados con la práctica asociativa: «fraternidad», trabajo en común en pos de «una idea elevada» y «progreso». Si bien rige un espíritu de camaradería entre los miembros, se distinguen jerarquías entre «las reputaciones más conspicuas de las letras», «inteligencias superiores», y los jóvenes, de quienes se espera que por medio de la «emulación», adquieran competencias artísticas.

Cuestión primordial para el funcionamiento asociativo es la introducción en su reglamento de la prohibición de «alusiones bajo cualquier forma á la actualidad política de los paises del Plata» («Ateneo del Plata», 30 de junio de 1858). Esta restricción, frecuentemente proclamada por algunos sectores del incipiente campo literario, responde a un clima de época marcado por el agotamiento ante una confrontación partidaria que parecería difícil de erradicar y la aspiración de promover la unión de la sociedad. La declaración deja entrever a su vez un reclamo de autonomía para la práctica literaria respecto de su utilización como instrumento de enfrentamientos por el poder. ${ }^{22}$

Semilla del escándalo, el precepto provocará la separación del Ateneo, al poco tiempo de su establecimiento. El rechazo de uno de sus miembros honorarios a causa de las afiliaciones políticas que profesa por parte de un grupo opositor suscita el conflicto y posterior quiebre de la asociación. En la crónica de la reunión se describe de este modo la razón de la discordia: «La política se había entronizado en el Ateneo (...) patrocinaba á algunos de sus miembros y coartaba á los otros en el uso de sus derechos» («Ateneo del Plata», 3I de julio de 1858$).{ }^{23}$

Los partidarios de una práctica literaria neutral, despojada de animosidades políticas, se organizan en una nueva red llamada Liceo Literario. Aunque el nombre de Blanco no aparece como integrante de esta asociación, podría suponerse, a la luz de comentarios futuros, que adhiere a sus principios. Arrasadas por las rivalidades, ninguna de estas instituciones llegará a desplegar actividad alguna, naufragando en las disputas alrededor de su conformación.

22 La postura de excluir a la política de la práctica de las letras está presente en la citada «Protesta» escrita por los colaboradores de La Ilustración... para desvincularse de las opiniones de Blanco acerca de la prensa argentina. Allí se lee lo siguiente: «No entraremos á analizar ni á refutar una por una, las ideas emitidas por nuestro colaborador, porque no siendo este semanario un periódico político -excluye toda polémica de ese género, y porque á pesar de los rencores civiles que ha acallado la fusión entre los hijos de esta tierra, todos los hombres eminentes que han figurado en nuestra prensa periódica, todos esos hombres llamados por Rosas y Urquiza "Salvajes Unitarios" y todos los que actualmente figuran honrosamente en ella, son considerados como hombres patriotas é incapaces de servir con su pluma á intereses mezquinos» (I6 de octubre de 1853). Entre otros muchos ejemplos, puede citarse además el programa mismo de El Estímulo. En su página de presentación se afirma: «Los momentos en que sale á luz nuestro periódico hacen más necesaria que nunca la declaracion de que su carácter es puramente literario. —La politica será absolutamente excluida de él, porque así lo exije el objeto que por base nos proponemos al fundar esta publicacion» («Declaración», 9 de febrero de 1858). Las cursivas pertenecen a Fajardo.

23 Auza explica el episodio y las desavenencias políticas en tiempos de la Secesión porteña de esta manera: «El suceso fue un capítulo más de la lucha política que dividía a los argentinos de Buenos Aires y las provincias, de liberales y federales. Precisamente la piedra del escándalo fue el federal Nicolás Calvo, director de La Reforma Pacifica, órgano que postulaba el entendimiento con la Confederación, y cuya recepción como miembro honorario se obstaculizaba» (I999: 130). Contra Calvo se alzaron Juan María Gutiérrez y Dardo Rocha, entre otros. Retirados del Ateneo los partidarios de la abstracción de la política, la asociación adquirirá un sesgo acorde al gobierno liberal de la provincia. 
Hacia el final de la década, Blanco publica por entregas en las páginas de Museo Literario su tercera y última novela, Luis y Estevan. Algo más jóvenes que él, Paz y Paganini, directores de la nueva revista, lo conocían de asociaciones previas e incluso, tal como más adelante quedará expuesto, le profesaban gran reconocimiento. La aparición de la primera entrega de su ficción en el número debut de la revista podría ser interpretada como una apuesta por parte de los realizadores a la experiencia de Blanco en la construcción de historias atrapantes para despertar el interés de los lectores. Completada la edición de su novela, el rastro de Blanco se pierde. La sistematicidad de su intervención se interrumpe. Posiblemente los escritos portadores de su diagnóstico de la práctica literaria por examinar permitan aproximar una respuesta que solo puede tener carácter hipotético para explicar su alejamiento. Ellos se delinean como piezas sugestivas, fragmentos que dejan avizorar una figura de autor y las problemáticas que atañen a dicha condición en el período.

\section{Pieza i: el artista ANTe el imperio de lo Superfluo}

Este apartado abordará el artículo titulado «La Moda, el Tono y el Talento» (I853:5-6), propuesto como primera pieza-fuente para perfilar a Blanco como autor, en tanto puede ser leída como una reflexión acerca del lugar del artista en la cultura en un trasfondo marcado por prácticas sociales afectadas ante una mayor oferta de bienes consumo y por nuevos lectores forjados por la prensa. Se trata de una sátira alegórica de la sociedad porteña, ambientada en un baile al que un personaje cronista, referenciado como el «sr B...» (5), asiste llevado por la curiosidad. ${ }^{24}$ En este encuadre ficcional, la coincidencia entre el nombre del cronista y la inicial del apellido del autor del artículo establece un juego textual en el que es posible apreciar una representación de este último fraguada por medio de un desdoblamiento.

La ficción escenifica una amena fiesta a la que el narrador-periodista asiste invitado, aunque de entrada se indica que no pertenece al círculo social allí reunido. Ajeno y deseoso de averiguar sobre los concurrentes, adopta un rol indagador para comprender las costumbres que los rigen. ${ }^{25}$ Sucesivamente, llaman su atención tres personajes que, nombrados a partir de ideas abstractas, ocupan posiciones contrastantes en un universo configurado por «notabilidades» ${ }^{26}$ y por seres insignificantes — «nulidades»—, según el reconocimiento social adjudicado a cada uno de ellos. Sobresalen por su encumbramiento «la Moda y el Tono», versiones femenina y masculina en los que se retrata un modelo de conducta imperante en la sociedad. La ignorancia respecto de ambos por parte del cronista irrita a los interlocutores a los que interroga — «En verdad, señor, no conoce usted á esa señorita?» (1853: 5) - y marca su desconexión de las redes de la sociabilidad distinguida. La reiteración de la palabra «notabilidad» y sus formas derivadas confiere un efecto irónico sobre las figuras en las que recae dicha valoración «aquella notabilidad, notabilísima de nuestras notabilidades» (6).

Los giros rimbombantes al presentar a la Moda portan cierta comicidad en la que subyace el cuestionamiento a la proclamación de lo frívolo como valor social: «Esa bellísima

${ }_{24}$ Creando un lazo cómplice con el receptor, el cronista comenta respecto de sí: «es preciso que mi lector amable (...) sepa (...) que soy muy curioso, muy investigador» (1853: 5), nos dice acerca de él, anticipando la pesquisa en la que se sumergirá.

25 De raigambre ilustrada, el estudio de las costumbres se convierte en un modo de evaluar el estado cultural de un pueblo y las prácticas que deben ser erradicadas para alcanzar la civilización. La crítica, en este sentido, forma parte del diagnóstico necesario para emprender una reforma.

26 Las cursivas empleadas en las citas pertenecen en todos los casos a Blanco. 
antorcha de nuestra ilustrada sociedad (...) es La Moda, única hija del poderosísimo señor Siglo de la elegancia» (5). Ella se entrega a la danza como actividad predominante — «Nosotros, las notabilidades del país no dejamos de bailar jamás» (5)—, rodeada de pretendientes a los que alienta su vanidad. Además de sus prácticas, la descripción de este personaje pone el acento en su vestimenta, para destacar lo ridículo y poco decoroso de su traje. ${ }^{27}$

Moderada hasta entonces, la crítica alcanza su punto de máxima reprobación al concentrarse en el personaje del «Tono», quien adolece de los mismos defectos que «la Moda», agravados por alardes de erudición que todos reverencian. Al igual que el título de su libro "Los capotes y las capasó [sic] sean [sic] las montañas del Paraguay» ${ }^{28}(6)$, los conocimientos de este personaje consisten en datos entremezclados, invenciones desopilantes y constantes equívocos que ponen de manifiesto su más absoluta incultura. Así, cuando el cronista comenta que acaba de llegar de Antuerpia, el Tono responde: «(...) bello país es ese, la capital de Entre Ríos. Yo estuve en él con ánimo de estudiar Griego, pero regresé enfermo a causa de una polémica que emprendí con el Papa, en inglés, que entonces residia alli, sobre la religión de los naturales, porque como usted ya sabrá, los entrerrianos son protestantes todos» (6).

Un tratamiento diferente recibe el tercer personaje aludido en el título, el «Talento», quien, según le comentan, es «un pobre diablo, sin fortuna, sin relaciones, (...) no nos familiarizamos con él» (6). Su menor desarrollo tiene que ver con su condición irrelevante, marcada por la carencia de dinero y de reconocimiento. En la simpatía del cronista hacia él puede interpretarse la identificación con lo que representa y un modo de atribuirse a sí mismo la capacidad, inteligencia y creatividad de este, pese a la devaluación de la que es objeto en ese contexto. El cierre del artículo con el fin del baile y un cortejo que sigue reverencialmente a «la Moda» y a «el Tono» constituye la instancia en la que aflora explícitamente la opinión del cronista: «Dios nos dé juicio y cabeza!» (6), exclama, renegando ante un mundo extraviado que se consagra a la vanidad y desprecia al verdadero artista.

A través de estos personajes, Blanco plasma su visión de los aspectos negativos de los fenómenos implicados en la modernización. El más visible de ellos, por su presencia en el orden cotidiano, es la moda, que, alentada por el ingreso de bienes extranjeros mediante la mayor fluidez del intercambio comercial en los años que siguieron a Caseros, opera una modificación de las costumbres, ocasionando un rotundo giro cultural. Manifestaciones de este cambio se evidencian en prácticas de elite modeladas por los numerosos manuales de urbanidad que proliferaron en Hispanoamérica hacia la segunda mitad del siglo XIX (Lander, 2003), impulsores, según Jesús Cruz (2010), de la cultura del consumo moderno. ${ }^{29}$ De allí que el tema de la moda, aparezca una y otra vez en escritos, ya sean entusiastas o críticos, datados a lo largo del período.

En la crítica de Blanco hacia el auge de la moda se advierte un distanciamiento respecto de la postura manifestada por los miembros de la Generación del 37. Como es sabido, en notas de La Moda y de El Iniciador, Juan Bautista Alberdi, Miguel Cané (p.) y Andrés Lamas profesaron su fe en ella como medio civilizatorio. También Sarmiento la asociará con la idea de progreso y mejora sociopolítica. Desde la perspectiva de estos primeros románticos, la renovación del atuendo de un individuo forma parte de un

${ }_{27}$ El comentario del vestido de «la Moda» es el siguiente: «su vestido largo, arrastraba de un estremo á otro del salón, enredando á su pareja, y tan descotado que la mas púdica vista del bailante podría penetrar en el santuario» (1853: 5).

28 Nótese que los errores de tiempo verbal y los neologismos son indicios de la ignorancia del personaje.

${ }_{29}$ En efecto, parte del reconocimiento del que goza el señor Tono, se vincula, según llega a informarse el cronista, con la posesión de diferentes carruajes, palcos en los teatros, entre otros bienes. 
programa que aspiraba a la reforma de costumbres locales aletargadas, herencia del pasado colonial, y como vía para fomentar el interés en los valores modernos. Se trata, según Víctor Goldgel, de un marcador exterior que se vincula en sistema con otros aspectos, indicadores de la civilización: «Modas vestimentarias, doctrinas políticas, peinados e ideas literarias, lejos de ser entidades heterogéneas constituían diversas manifestaciones de una cultura unitaria y orgánica. Por lo menos hasta mediados del siglo xIx, esta forma de concebir la cultura fue bastante común en el mundo hispanoamericano» (2013: 137-138).

A diferencia de los fundamentos de aquellos proyectos, la sátira de Blanco esboza una coyuntura en la que la moda adquiere vida propia, emancipándose de las funciones asignadas anteriormente para devenir en un valor en sí mismo o nuevo criterio de diferenciación que eleva lo superficial y menosprecia la inteligencia y la creación. En el «temor hacia lo banal», Cecilia Rodríguez Lehmann advierte una profunda preocupación alrededor de «las funciones y el lugar de lo literario dentro del proceso de construcción republicana» (2013: 9), lo que se ajusta con acierto a la intención de Blanco, quien representa, en la marginalidad del personaje del «Talento», el desplazamiento del letrado de su papel de guía cultural en un ambiente marcado por el materialismo. La percepción del hombre de letras como «apóstol secular» o «educador del pueblo», gestadas en la Ilustración (Altamirano, 2008: 15) y vigentes a lo largo de todo el siglo XIX, sustentan el modo de percibir su labor por parte del autor, evidenciado en el propósito mismo de su artículo de costumbres. Según el diagnóstico planteado allí, este cometido se encuentra en crisis por las condiciones de una época en la que el mercado dicta valores y comportamientos.

Producto de la mutación modernizadora, el personaje del Tono se perfila como el falso letrado. Caracterizado con mayor profundidad por el cronista, su recreación no solo remite al «petimetre», practicante de los modales atildados prescriptos, ${ }^{30}$ sino también a un tipo humano que en la época se designaba como «erudito a la violeta», mote satírico acuñado por el español José Cadalso en su texto homónimo de i772. Goldgel interpreta la apelación a esta figura como síntoma de una crisis ligada a los efectos no deseados del proceso de democratización del conocimiento, iniciado a partir de la Ilustración, con sus salones y cafés y con la divulgación activada por la prensa, tanto en el Viejo como en el Nuevo Mundo (2013: 127). Así, en «el señor Tono» pueden reconocerse a aquellos lectores producto de la expansión de la lectura, propiciada por la fuerza pujante del periodismo, de impronta decisiva en Buenos Aires tras la derrota de la tiranía rosista. Su procesamiento del flujo de información diversa del que la prensa es portadora - 0 «lectura extensiva» en términos de Chartier (1994) - se lleva a cabo de manera deficiente en su caso.

Blanco retrata en este personaje a un mal lector que confunde datos de procedencia diversa en una mezcolanza inadmisible, enunciada para aparentar, pero que, pese a ello, llega a convertirse en autor y autoridad, reverenciada por otros tantos como él. Este pseudo sabio disputa el lugar que debería recaer sobre el verdadero, el Talento, desplazado por los cambios provocados por la modernización. La crónica despliega de este modo una pugna por la autoridad discursiva, que se experimenta arrebatada de su poseedor tradicional por advenedizos de dinero e incultos que banalizan la república de las letras. Es clara, de acuerdo con lo expuesto, la proyección del propio autor en el personaje del «Talento», verdadero doble de él, pues aparece delineado con los mismos rasgos: marginal, ignoto y sin fortuna.

Si «la posición social del escritor depende del concepto (...) que los otros grupos elaboran en relación con él» (Altamirano, Sarlo, 1993: 66), este círculo de notabilidades nada

30 De hecho, el nombre mismo de Tono remite también a los manuales que instruyen sobre la etiqueta y el refinamiento. 
sabe acerca del auténtico creador. Blanco pone de manifiesto las consecuencias nefastas de un público poco cultivado, estableciendo una relación crítica con esos lectores de quienes depende su afianzamiento como autor. Estos receptores, ampliación del círculo culto, no poseen aún la disposición ni las competencias para la comunicación literaria y confinan al artista al solipsismo. Así, al igual que el personaje con el que el cronista se identifica, el resultado es el aislamiento. Es posible vislumbrar además en el mutuo desconocimiento entre el creador y estas elites una percepción exagerada alrededor del creciente anonimato en las relaciones sociales en una ciudad en expansión.

Finalmente, la configuración de la pequeña sociedad recreada sobre la base de la oposición «notalibidades» $\mathrm{y}$ «nulidades» tiene como correlato otro contraste vertebrado según la posición económica a la que los personajes pertenecen. Mientras la Moda y el Tono representan estratos opulentos, el Talento se caracteriza por la carencia de bienes de lujo, en una posible alusión a la extracción de clase predominante entre los nuevos escritores emergentes. Se distinguen también por sus valores: los primeros se definen por su desenfrenado materialismo; el segundo, por el cultivo de valores relacionados con la elevación del espíritu en la creación.

\section{Pieza dos: LA ENCRUCiJAdA DE Un PROYeCto CREAdor}

Entre 1856 y 1859, Blanco escribe las tres novelas que integran su obra: Una venganza funesta, novela orijinal (1856), Emeterio de Leao, continuación de Una venganza funesta, novela original (1857a) y Luis y Estevan (1859), las dos primeras en formato libro y la tercera por entregas en la revista Museo Literario. Este apartado se propone dar cuenta de la existencia de un "proyecto creador» (Bourdieu, 197I) consistente en su producción para luego examinar, en un conjunto de rastros inscriptos en ella, su conflictiva articulación con las estrategias de divulgación comercial puestas en juego. Se consideran también aquí los paratextos que las acompañan, como espacios en que el autor presenta su trabajo al público, construye imágenes de sí como productor y justifica sus opciones artísticas.

Publicadas en años sucesivos, las tramas de las dos primeras novelas se sustenta en un plan de escritura de trazos bien definidos. Ello se detecta no solo en la continuidad, indicada en el título, de las líneas argumentales de la historia en la siguiente narración, sino también en la presentación gradual de una crítica moralizante de profundo alcance. $3^{3+}$ Por estos rasgos es posible afirmar que Blanco se perfila como un escritor hábil, que ha ideado su obra detenidamente, disponiendo de los recursos de la intriga y los ha orientado en función de sus necesidades expresivas. La profundidad para establecer la causa de los vicios propagados en la cultura porteña de su tiempo distingue su producción de las demás novelas del período, mayormente centradas en temáticas ligadas a calaveras burladores, coquetas inmorales, hijos abandonados, matrimonios contraídos por interés. ${ }^{32}$ Nuevamente la reforma de las costumbres convoca la labor del autor, acorde en esto con la poética emergente de la novela, definida por el propósito de moralizar al lector (Molina, 20II).33

3I Podría decirse que se advierte una progresión e intensificación de los planteos morales de Una venganza funesta... en Emeterio de Leao. Mientras la primera aborda diferentes problemas y crea las condiciones marco para el mensaje que al autor le interesa comunicar, la segunda se adentra plenamente en el vicio que quiere combatir.

$32 \mathrm{Si}$ bien algunos de estos asuntos están presentes en las anécdotas de Blanco, el autor les da un tratamiento más profundo indagando en sus causas.

33 Molina reconstruye los debates entre los escritores argentinos para la inclusión de la novela en el sistema literario nacional, destacando el consenso alrededor de la función moralizante. 
Para Blanco, el mal que aqueja a su entorno es el «EGOÍSMO SOCIAL», diagnóstico que escribe con mayúsculas en Emeterio de Leao... para dar énfasis y contundencia a su prédica. Con esta fórmula el autor se refiere a la falta de solidaridad por parte de muchos compatriotas de posición social acomodada hacia aquellos sectores sumidos en la miseria. Así, el punto culminante de sus narraciones se localiza en la regeneración del protagonista nombrado en el título, un hombre pobre y marginado que logra sobreponerse al crimen gracias a testimonios de caridad recibidos de miembros de la elite; ${ }^{34}$ esos actos de piedad lo devuelven a la senda del bien confiando nuevamente en la humanidad. Aunque esta resolución muestra una imagen positiva de las clases altas, los comentarios del narrador dejan en claro que, lamentablemente, se trata de honrosas excepciones, pues el desarrollo de la historia se encuentra atestado de pasajes en los que se reprende la indiferencia de esas "piedras humanas», frívolas, ante las privaciones y sacrificios del indigente.

Editadas estas dos primeras novelas sin prólogo, decisión que más tarde Blanco fundamentará al escribir uno para Luis y Estevan en el hecho de que esas presentaciones les parecen dictadas por la «falsa modestia» e «hipocresía», Emeterio de Leao... contendrá, sin embargo, un epílogo, titulado «ii Que lo lea el que quiera!!» y una nota al pie, dispuestos por la necesidad del autor de dirigirse en forma directa a su público y reforzar los puntos de vista expuestos en sus ficciones. Como el título de dicha sección final anticipa, sus palabras estarán despojadas de retórica.

Ambos paratextos se originan en una lectura previa a la edición del libro realizada por un foro de colegas. Este episodio mencionado en el epílogo es el que impulsa su escritura como probablemente también la colocación de la nota en el cuerpo de la novela, realizada, según esta interpretación, en forma posterior a haber concluido la narración. Las justificaciones respecto de la demora del segundo tomo de la novela con las que comienza el epílogo aluden veladamente a estas discrepancias: «Incidentes relativos á la imprenta, $\mathrm{y}$ otros relativos a nosotros, nos han impedido cumplir antes de ahora con nuestros suscriptores» (I857: 185). Puede conjeturarse que en ese lapso, Blanco incluye la nota al pie, desprendiéndola de un pasaje en que recrudece su crítica en torno del egoísmo social.

Si bien en el epílogo no se especifica si esos lectores están formalmente ligados a la labor de edición, como reguladores del contenido, o si son pares a quienes el autor consultó espontáneamente, los comentarios recibidos y la réplica del autor, plasmados en los paratextos, se convierten en datos clave para pensar las tensiones entre el proyecto creador y un modo de puesta en circulación de sus textos que apuesta a la conquista de público. En desacuerdo con las observaciones planteadas en esa instancia de lectura preliminar a la publicación, Blanco escribe el texto de cierre de su novela para reforzar su perspectiva ante un eventual público: «Algunos amigos nuestros han creído ver en esta obra un ataque á la sociedad. Es un error de apreciacion. Tenemos el derecho de criticar lo malo» (I86). La desafiante conclusión — «Si alguien se reconoce en la pintura culpe (...) á si mismo: de ningun modo al pintor» (I86) - potencia el tono del título que evidencia su irascibilidad ante la incomprensión y mala recepción de su creación. Lo cierto es que no teme ofender la reputación de las clases pudientes, entre las que se cuentan los potenciales lectores del libro.

Contracara de ese desdén que deja librada la iniciativa de lectura exclusivamente en manos del lector, el autor manifiesta un claro interés en el alcance de sus obras. Una

34 Mientras el episodio de recuperación de Emeterio se narra en Una venganza funesta..., la novela siguiente centrada en este personaje lo presenta como benefactor incondicional de la pareja que lo ayudó, lo que permite al narrador insistir en la necesidad de compromiso y auxilio del prójimo. 
mirada atenta a estos dos primeros libros revela que novelista y editor trabajan conjuntamente en la colocación exitosa de ellos entre el público. Ambas obras, que se venden por suscripción, están concebidas para mantener cautivo a sus compradores, ofreciéndoles prolongaciones de la historia, desarrollo de personajes secundarios como protagonistas de la siguiente, resoluciones de conflictos inconclusos, entre otros incentivos. Teniendo en cuenta estas operaciones, podría afirmarse que Blanco parece comprometer todos sus esfuerzos creativos para capturar la curiosidad de sus lectores. Él mismo anuncia en el polémico epílogo una nueva novela, la cual, quizás, a causa de las divergencias alrededor de su Emeterio, quedará sin concreción: «daremos después la tercera y última parte de esta obra bajo el título ADOLFO AGUILAR, donde hallarán los lectores, sus antiguos y otros nuevos personajes» (I857a, t. II: 186). Por su parte el editor es un agente activo, que dispone anuncios y condiciones de suscripción como, por ejemplo, el colocado al finalizar Una venganza funesta:

\section{NOTA DEL EDITOR}

El señor Blanco ha empezado á escribir la continuación de esta obra, bajo el título Emeterio de Leao, que muy pronto daremos á la prensa.-Como solo se tirará un número limitado de ejemplares, rogamos á los señores que deseen suscribirse, ocurran hasta el I ${ }^{\circ}$ de Febrero de 1857 á esta Librería de Juan Muñoz, calle del Perú número 134 o á la Imprenta Americana, calle de Santa Clara número 62. (I856, t. II: I70)

Sobre la base de lo analizado, podría afirmarse que la conflictividad de la autoría en Blanco reside en el desencuentro entre un proyecto moralizador que dirige severas acusaciones a los sectores sociales que conforman su potencial público, y los esfuerzos por sostener un grupo lector seguidor de sus obras. Esta experiencia lo confronta con el hecho de que la independencia de criterio está reñida con la lógica de venta. La nota al pie incluida en la novela despliega una diatriba contra un lector imaginario que, molesto por sus afirmaciones, profiere impugnaciones hacia él. Su defensa apela a las diferencias de clase y valores:

Pero á estas reflexiones exactisimas los ricos responden «és un pobrete el escritor, y nos hace la guerra por envidia».

¡Se equivocan!.... Somos ricos también: por que la riqueza del hombre no és el capital, sino las mas ó menos necesidades que tiene.

Ademas, mientras Dios nos conserve la cabeza y la mano con que tenemos la pluma, no necesitaremos de ningun favor. La voluntad y el trabajo, son nuestro capital inagotable. A él nos atenemos siempre. Nosotros atacaremos el EGOISMO como la base de toda desmoralizacion social: como la perversion del corazon. Respetamos á los hombres que hacen un uso noble de su riqueza: despreciamos y atacamos á los que especulan con la miseria: á los que la pervierten con su oro (I857a, t. II: I4).

Suponiendo que estos detractores atribuyen las críticas planteadas en el libro al resentimiento por los apuros vinculados con la posición económica que ocupa su autor, Blanco traza una oposición entre dos nociones de capital, una ligada al oro (la del lector rico y agraviado) y otra ligada al pensamiento y la escritura (la de él, representada en la cabeza y la pluma). En su orgullosa definición como escritor poseedor de otro tipo de riqueza, 
vuelven a hallarse tópicos abordados en la nota «La Moda el Tono y el Talento». El autor prefiere afrontar la pérdida de lectores antes que la renuncia a sus convicciones.

Tras un año sin escribir novelas, Blanco, que había dejado sin concretar el plan novelesco que había anunciado como continuidad de Emeterio, publica por entregas su última ficción titulada Luis y Estevan, en la revista Museo Literario. Presenta allí una trama independiente respecto de las precedentes y deja de lado la fórmula del «egoísmo social» en pos de otras problemáticas. En la circulación de esta producción por medio de la prensa especializada y no como en los casos anteriores en formato libro, se entrevé nuevamente una apuesta a la expansión de su público lector.

Como se ha dicho antes, esta novela es la única que presenta una carta dedicatoria dispuesta como prólogo. Quizás luego de la polémica provocada por Emeterio de Leao... el autor parece necesitar justificar la escritura de una nueva novela. Declara en este marco que en el contexto de luchas políticas y de imitación de la vida europea comprueba la necesidad de asumir un compromiso en pos de la educación moral de la juventud.

\section{Pieza 3: Algunas reflexiones sobre la carrera literaria}

El mismo año que Blanco publica, en medio de las referidas discordias, Emeterio de Leao..., un escritor siete años más joven que él, Carlos L. Paz, le dedica su primera novela Santa y mártir de veinte años. ${ }^{35}$ En respuesta al reconocimiento del que es objeto, responde con una carta, que el principiante adjunta como prólogo para la presentación de su libro. De este modo, la epístola, si bien destinada a un interlocutor específico, adquiere con esta disposición, posiblemente prevista, dimensiones de carta pública, es decir, concebida para ser puesta en circulación entre los lectores e interpelar, al mismo tiempo, a los demás actores del campo literario. ${ }^{36}$

Animado por la intención de advertir a quien se inicia en la carrera literaria alrededor de los numerosos «obstáculos» o «espinas» que le esperan, Blanco evidencia en este texto una conciencia aguda respecto de los condicionamientos a los que los escritores emergentes de su tiempo están expuestos. Con el objeto de templar el espíritu del joven y exhortarlo a no claudicar, descubre ante él un panorama adverso donde los rasgos dominantes del público lector, la práctica literaria y el sistema de relaciones en que ella se inserta, las reseñas periodísticas, la politización del letrado y la injerencia de la política en la producción y recepción de las obras, se delinean como una serie de escollos que deberá sortear.

Sus reflexiones en torno a «la sociedad para la cual escribe» (I857b: II) reiteran las percepciones sobre el lector desarrolladas en su artículo satírico y en los paratextos de sus novelas. La entrega a la frivolidad, patente en el modo de vestir y en prácticas estériles, define el comportamiento del público de elite. Sin elevación espiritual, compensan su vacío con la posesión de dinero. Planteando la cuestión de la comunicación literaria en términos de posición económica, contrapone a este grupo con el colectivo «los escritores», delineado por la falta de riqueza. La desigualdad torna compleja la situación del artista, debido a la relación de dependencia respecto de esos lectores, «somos pobretes que especulamos

35 Blanco y Paz se conocen desde su participación en el Club Parroquial de Montserrat. Paz, por su parte, será, más adelante, uno de los directores de Museo Literario donde Blanco publica Luis y Estevan (I859).

36 Cabe aquí llamar la atención en el hecho de que la dedicatoria de Paz permite reconocer el lugar de Blanco como referente de las nuevas promociones. Otra fuente que apuntaría en esta dirección es la reseña que Francisco Bilbao publicó en la Revista del Nuevo Mundo, en la que expresa: «Su obra merece aplauso y estímulo. Ella honra á la nueva generación, cuya literatura debe corresponder al nuevo órden de moralidad en la política» (I857: 383). 
con esos hombres» (1857b: 8), ${ }^{37}$ expresa, dejando entrever no solo una cuestión de diferencias de valores entre materialismo y arte, que ocasiona la incomprensión de tales interlocutores, sino también una clara vinculación entre actividad literaria y ganancia.

Las apreciaciones alrededor del sistema de relaciones en que se inserta la práctica literaria - o campo literario - ponen de manifiesto la asimetría existente entre los actores que lo componen, al describirlo como espacio constituido por posiciones encumbradas, influyentes e investidas de legitimidad y otras de menor relevancia. Blanco reconoce, sin consignar nombres concretos, el lugar de mérito alcanzado por algunos hombres de letras. Constatado ello, no asume ante estas figuras una actitud reverencial sino de reproche, debido a la indiferencia que profesan respecto de las producciones de los que se inician en la creación. Previene, así, al debutante sobre: «La criminal decidia de nuestros pocos literatos que abandonan á sus solos esfuerzos en esa senda una juventud intelijente y activa que debieran dirijir con su esperiencia, que debieran proteger con su influencia» (1857b: 7 ). Su reclamo parece estar destinado a los integrantes de la Generación del 37, pues, como señala Jorge Myers, hacia i852, los principales escritores de este grupo «se transformaron en figuras de referencia ineludible para los más jóvenes que se habían formado durante la era rosista y que por ello mismo poseían —al menos en un principio - un horizonte intelectual menos amplio que el de sus antecesores» (2003: 310)..$^{8}$

La recriminación hacia los escritores venerados por la opinión pública no termina allí. Otro cargo que les imputa es haber virado sus carreras hacia la militancia partidaria: «La ambicion (...) de las posiciones elevadas, de las luchas políticas absorven toda la vitalidad de esos hombres» (1857b: 7). Como si se tratara de una premonición, Blanco previene al novato acerca del descuido de los autores consagrados hacia sus sucesores, lo que lo enfrentará con una «guerra sorda» y "pasiva» y lo condenará a «vejetar en la oscuridad» (7). Lo alerta además contra el peligro de ser introducido en la contienda política.

Trazando una contraposición tajante entre el escritor y el político, Blanco aboga por un espacio literario autónomo, exento de partidismos ajenos a la especificidad artística. No obstante, a su pesar, constata que la política todo lo contamina, pues no solo acapara a las figuras consagradas sino que también se convierte en un factor decisivo para la evaluación de las obras por parte de críticos y público. Consecuencia de la falta de una palabra autorizada es la aparición de otros autores que, elevados por las crónicas locales, ejercen el rol de críticos sin más criterio que «el prisma de sus pasiones, ó de sus intereses» (I857b: II). La valoración de la producción está teñida por la intromisión de juicios que prescinden de lo estético para privilegiar simpatías o antipatías partidarias. Prejuicios y animosidad dominan en la lectura hecha también por el público: «¿Es partidario de fulano? - no?— ¡Ah! entonces no leo lo que usted escribe» (I857b: 8). Incapaces de forjar un pensamiento propio, estos sectores quedan a merced de publicistas, cronistas locales que, sin demasiado conocimiento, influyen en su parecer. Se delinea con pesimismo una práctica literaria influida por lo político, cuyos enfrentamientos, como se ha referido, atraviesan todo el período y no ofrecerán las condiciones propicias para el ideal del autor y de quienes piensan como él.

37 Las cursivas son del autor

38 Puede volverse en este punto sobre el episodio polémico suscitado por el artículo de Blanco «La prensa del país» para conectar la afirmación de Myers con la respuesta del resto del equipo de colaboradores en defensa de los nombres de la Generación del 37. A esto podría agregarse que, en los números siguientes, La Ilustración Argentina comienza a publicar una semblanza biográfica y laudatoria de Mitre y Sarmiento, acompañadas por los retratos grabados de ambos. Como ejemplo del tono laudatorio, se lee: «Sarmiento como casi todas las ilustraciones intelectuales que honran a la república argentina» («Domingo Faustino Sarmiento», I6 de octubre de I853). 
La proclamación de la autonomía respecto de la política debe a su vez inscribirse en una coyuntura de reformulación de programas dentro del incipiente campo literario. En la defensa de la separación de la actividad intelectual y creadora de las luchas por el poder se puede notar un claro distanciamiento en relación con el legado de la Generación del 37 , el cual continúa vigente después de I852. Estos nuevos posicionamientos remiten a lo que Myers ha descripto como una paulatina mutación de la concepción de la literatura ligada a la militancia ideológica y política, desarrollada por los románticos de 1830, hacia una representación que aboga por la especificidad de la práctica literaria, proponiéndola como una «actividad superadora de las escisiones facciosas que agitaban a la sociedad argentina» (2003: 323). En esta línea, Auza considera que se trata de un nuevo modo de entender lo político, que trasciende las divisas partidarias, «Hay sí una política que (...) tiene cabida, pero es la política del engrandecimiento nacional aquella que se refiere al futuro del país, a su destino» (1999: 50). Por su parte, Molina también nota la recurrencia del objetivo de trabajar mancomunados por encima de las diferencias ideológicas entre los participantes del movimiento asociativo posterior a Caseros (20II: 97).

En el programa que Blanco explicita en su carta hay una estrecha vinculación entre literatura y nación, puesto que ella juega un importante papel en la construcción de un futuro civilizado: «es la vida del porvenir (...) corrigiendo los abusos que se transmiten del pasado, ilustrando las mayorias, enseñando á los hombres á ser ciudadanos, á ser morales las costumbres» (I857b: 9). Se deposita entonces en la creación artística un propósito moral, tendente a forjar al ciudadano, como forma de contribuir a la pacificación de la sociedad.

A lo largo de su exposición, Blanco ofrece un abanico de autofiguraciones autoriales, muchas de ellas estrechamente derivadas del diagnóstico que ha diseñado. Partiendo de una imagen inicial ligada a la declaración «mi palabra vale poco» (1857b: 5), que patentiza el sinsabor ocasionado por la posición marginal que ocupa, la figura de Blanco se agiganta hasta ocupar ese lugar de guía dejado vacante por el desinterés de los autores faro. Se infiere del gesto mismo de su crítica a la novela de Paz y de las recomendaciones sobre las espinas en la carrera de las letras, la adopción de ese rol de referente de la juventud, definiéndose para ello como un hombre de «esperiencia» (I857b: I2). En los consejos brindados se oyen ecos de sus propias frustraciones, heridas recientes que no han cerrado, réplicas dirigidas a críticos de su trabajo o protestas por indiferencia o incomprensión.

Tras ese propósito altruista — «no ha de encontrar interes de ningun género que las dicte» (I857b: II) - de alentar y orientar al joven con vocación literaria, de construir una literatura nacional, quizás Blanco aspire a un puesto fundacional de patrocinador. Comprometido con una labor pedagógica, sus apreciaciones sobre la novela de Paz, lo muestran agudo para evaluar diferentes aspectos de la narrativa, basándose en juicios estrictamente composicionales que lo distinguen como experto. Cómodo con el lugar de maestro, Blanco se perfila deseoso de alcanzar una aclamada reputación.

\section{LA CONFLICTIVIDAD DEL ESCRITOR EMERGENTE EN UN CAMPO LITERARIO EN TRANSICIÓN}

Los testimonios ofrecidos por Blanco aportan datos clave para una sociología de la cultura del período de la Organización Nacional, especialmente para la reconstrucción del proceso de conformación del campo literario argentino. A partir de la comprensión de los condicionamientos inscriptos en la coyuntura por parte del autor, es posible concebir explicaciones acerca de la experiencia de una promoción de jóvenes literatos, que focalicen en los aspectos conflictivos que debieron afrontar. 
Un panorama marcado por discrepancias políticas irreconciliables e interminables, que reclutaron del ámbito de las letras a quienes eran considerados sus referentes, constituye el fenómeno más visible de la voracidad con que la lucha en pos de la construcción del Estado nación solía ser experimentada como prioritaria por los intelectuales de esta etapa. Las rivalidades imperantes en la esfera del poder tendieron a interferir actividades ajenas a la militancia facciosa, tales como la literatura, sofocando sus reclamos de autonomía y disgregando sus asociaciones.

Cambio social de incidencia directa en la práctica literaria, la expansión limitada del público tuvo más un carácter levemente cuantitativo que cualitativo, es decir, aportó lectores sin destrezas para la comunicación literaria. Estos nuevos destinatarios, que no pertenecen al círculo culto, ponen de manifiesto incompetencias, que alertan acerca de los efectos no deseados de la modernización. No están preparados para procesar el cúmulo de información ante la efervescencia de impresos.

Así, si bien la intensa actividad alrededor de las bellas letras a través de sus revistas y modos de autoorganización hizo surgir, entre 1852 y 1880, «los rudimentos de un campo literario» (Myers, 2003: 305), no se logra concretar el ideal de un ámbito diferenciado, definido por su autonomía. Otras cuestiones relacionadas con tal aspiración, como la profesionalización de los productores culturales, no encuentran viabilidad durante la primera década del período, centralmente debido a la aún pendiente emergencia de un público específico y a la vez más numeroso.

La trayectoria de Blanco puede ser considerada epítome de todas estas limitaciones en tanto la marginalidad que caracteriza su posición le permite percibir la problemática que durante esos años afectó a quienes incursionaron en la carrera de las letras de manera más compleja que las plumas encumbradas. ${ }^{39}$ Surcados por múltiples incompatibilidades y tensiones, sus posicionamientos respecto de la práctica literaria, asumidos en sus escritos y proyecto creador, evidencian la conflictividad del escritor emergente en una transición hacia la diferenciación de la actividad.

Procurando trazar dicho proceso desde instancias previas a la cristalización de fenómenos de carácter más definido, Paulette Silva Beauregard subraya que si bien «Las investigaciones hispanoamericanas han privilegiado la época modernista en la que se supone que se dan los cambios más radicales vinculados al proceso de autonomización de la literatura y de la profesionalización del escritor», no debe perderse de perspectiva el hecho de que «a lo largo del siglo xix hubo un esfuerzo sostenido de muchos letrados por vivir de la pluma, para la cual apelaron a muy diversas estrategias y echaron manos de formatos y géneros exitosos (...) como el folletín» (2007: XVII).

La recuperación de la figura de Blanco posibilita evaluar la experiencia del escritor en el período previo a la configuración de una estructura más afianzada para la práctica. La apuesta por atraer lectores, plasmada en tramas novelescas que se prolongan en el siguiente libro y en la publicación por suscripción o por entrega en medios impresos especializados, que dan cuenta tanto de su búsqueda de generar ingresos con su producción como de ejercer ese rol de guía moralizador, tiene como contrapartida una relación problemática con el público al que considera frívolo, por su fervor hacia artículos de consumo ofrecidos en un mercado floreciente, e inculto y carente de destrezas para el procesamiento de los textos. Así, el contenido de su crítica reformadora de las costumbres ofende la reputación que sostiene una imagen positiva de las elites. E1 modo de concebir a este grupo y su representación de la tarea del escritor, plasmados

39 Se hace referencia aquí estrictamente al período de la Organización Nacional dado que es cierto que la 
en sus obras, lo exponen al rechazo, recordándole la dependencia del escritor de esa nueva clientela. La contraposición entre materialismo e incultura / valores estéticos y espirituales, se profundiza en una diferencia de clase social, entre lectores adinerados / escritor pobre y trabajador, autofiguración en la que es posible entrever una vinculación entre escritura y trabajo. En el reproche hacia el oro de estos sectores como elemento corruptor puede leerse la imposibilidad de conjugar moralidad y mercancía. Se advierte en él una posición ambivalente hacia el incipiente mercado literario: por un lado, está interesado en divulgar su obra con un propósito moral y pecuniario a la vez y, por otro, reivindica la libertad para crear según su propio designio.

Vocero de la autonomía de las bellas letras, Blanco promueve, junto a otros escritores, un nuevo programa y concepción de la literatura dentro de su ámbito. Polemiza con el legado de la Generación del 37 cuyas obras portan un compromiso político partidario, para embanderarse en la causa de una literatura unificadora de la sociedad y dedicada a la tarea constructiva de formación del ciudadano. Mediante la defensa de estos principios procura conquistar prestigio entre la fracción compuesta por las nuevas promociones. Sin embargo, las condiciones de época le impedirán gozar del reconocimiento, y sus seguidores se dispersarán.

Estudiada aquí como caso, la figura de Blanco da cuenta de los avatares de una generación de jóvenes cuyo ejercicio literario se vio afectado por la modernización y la coyuntura política.

\section{Bibliografía}

\section{Fuentes primarias}

Bilbao, Francisco (1857), «Emeterio de Leao», Revista del Nuevo Mundo, n ${ }^{\circ}-2,383$.

Blanco, Ángel Julio (1853), «La Moda, el Tono y el Talento». La Ilustración Argentina, $\mathrm{n}^{\circ} 3$. (1853), «La prensa del país». La Ilustración Argentina, $\mathrm{n}^{\circ} 5$.

- (1856), Una venganza funesta: Novela original, Buenos Aires, Imprenta Americana.

- (1857a), Emeterio de Leao: Continuación de Una venganza funesta; Novela orijinal, Buenos

Aires, Imprenta Americana.

— (1857b), "Carta a Paz", en Carlos L Paz. Santa y mártir de veinte años. Buenos Aires, Imprenta de La Reforma, I857, pp. 5-I2.

- (1859), Luis y Estevan: Novela de costumbres (1859), Museo Literario: Periódico semanal de literatura en general, teatro y modas, Buenos Aires, Imprenta de Mayo.

Fajardo, Heraclio (I858), «La Dirección», El Estímulo, nº i, p. I.

- (I858), «Declaración», El Estímulo, n I, p. 8.

$\mathrm{S} / \mathrm{F}$ (1858) «Ateneo del Plata», El Estímulo, n 18.

(1858) «Ateneo del Plata», El Estímulo, n 21.

- (1858) «Ateneo del Plata», El Estímulo, n 25.

Huergo, Palemón, Alsina, Adolfo, et. al (I853), «Protesta», La Ilustración Argentina, n 6, p. I.

Fuentes secundarias

Altamirano, Carlos (2008), «Introducción general», en Jorge Myers (ed.), La ciudad letrada de la conquista al Modernismo, en Carlos Altamirano (dir.), Historia de los intelectuales en América Latina, Buenos Aires, Katz.

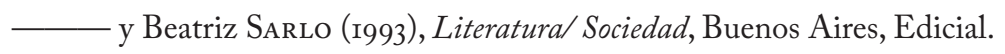


AuzA, Néstor (1999), La literatura periodística porteña del siglo XIX. De Caseros a la Organización Nacional, Buenos Aires, Confluencia.

AA.VV. (1980-1986), Capitulo. La historia de la literatura argentina, Buenos Aires, CEAL, 4 v.

BAtticuore, Graciela (2006), «La formación del autor. Apuestas, retos y competencias» en Alejandra Laera, Martín Kohan (comps.), Las brújulas del extraviado. Para una lectura integral de Esteban Echeverría, Rosario, Beatriz Viterbo.

Bourdieu, Pierre (I97I), «Campo intelectual y proyecto creador», en Problemas del estructuralismo. México, Siglo XXI.

Chartier, Roger (1994), Libros, lecturas y lectores en la Edad Moderna. Madrid, Alianza.

Cutolo, Vicente (I968-1985), Nuevo diccionario biográfico argentino (I750-1930), Buenos Aires, Elche.

Cruz, Jesús (20I0), «La definición de los modelos de conducta burguesa en la España del siglo XIX» en Pierre Civil, Françoise Crémoux (coord.), Actas del XVI Congreso de la Asociación Internacional de Hispanistas. Nuevos caminos del hispanismo, Madrid / Frankfurt, Iberoamericana / Vervuert, vol. 2. https://bit.ly/3r24 $\mathrm{N}_{5} \mathrm{P}$

Eujanián, Alejandro (1999), «La cultura: público, autores y editores» en Marta Bonaudo (dir.), Nueva Historia Argentina, Liberalismo, estado y orden burgués (1852-1880), Buenos Aires, Sudamericana, IV, pp. 545-603.

Goldgel, Víctor (2013), Cuando lo nuevo conquistó América. Prensa, moda y literatura en el siglo XIX, Buenos Aires, Siglo XXI.

GonzÁlez Stephan, Beatriz (I995), «Modernización y disciplinamiento. La formación del ciudadano: del espacio público al privado» en Beatriz González Stephan, Javier Lasarte y María Julia Daroqui, (comps.), Esplendores y miserias del siglo XLX. Cultura y sociedad en América Latina, Caracas, Monte Ávila Editores, pp. 431-455.

Halperin Donghi, Tulio (20I2), Una nación para el desierto argentino, Buenos Aires, Prometeo.

Hora, Roy (2012), «Introducción. Una nación para el desierto argentino: algunas claves para su lectura», en Tulio Halperin Donghi, Una nación para el desierto argentino, Buenos Aires, Prometeo, pp. 9-30.

Lander, María Fernanda (2003), Modelando corazones: sentimentalismo y urbanidad en la novela bispanoamericana del siglo XIX, Rosario, Beatriz Viterbo.

Lettieri, Alberto (I999), «De la "República de la Opinión” a la "República de las Instituciones”» en Marta Bonaudo (dir.), Nueva Historia Argentina, Liberalismo, estado y orden burgués (1852-I880), Buenos Aires, Sudamericana, IV, pp. 97-I60.

Molina, Hebe (20II), Como crecen los hongos. La novela argentina entre I838-1872, Buenos Aires, Teseo.

Myers, Jorge (2003), “Aquí nadie vive de las bellas letras”. Literatura e ideas desde el Salón Literario a la Organización Nacional» en Julio Schwartzman (dir.), La lucha de los lenguajes, en Noé Jitrik (dir.) Historia crítica de la literatura argentina, Buenos Aires, Emecé.

Ortiz Gambetta, Eugenia (2013), Modelos de civilización en la novela de la Organización Nacional (I850-I880), Buenos Aires: Corregidor.

Rodríguez Lehmann, Cecila (2013), Con trazos de seda. Escrituras banales en el siglo XIX, Caracas, Fundavag Ediciones.

RojAs, Ricardo (1948), Historia de la literatura argentina. Ensayo filosófico sobre la evolución de la cultura en el Plata, 5 v., Buenos Aires, Losada.

SÁвAто, Hilda (2008), «Nuevos espacios de formación y actuación intelectual: prensa, asociaciones, esfera pública», en Jorge Myers (ed.), La ciudad letrada de la conquista al Modernismo, Carlos Altamirano (dir.), Historia de los intelectuales en América Latina, Buenos Aires, Katz.

Salvatore, Ricardo (2010), «Pena de muerte y liberalismo», Subalternos, derechos y justicia penal, México, Gedisa, pp. 163-I99. 
Schwartzman, Julio (dir.) (2003), La lucha de los lenguajes, Noé Jitrik, Historia Crítica de la Literatura Argentina, Buenos Aires, Emecé.

Silva Beauregard, Paulette (2007), La trama de los lectores. Estrategias de la modernización cultural en Venezuela (siglo XIX), Caracas, Fundación para la Cultura Urbana. 